\title{
Intention to Quit Tobacco Use and its Determinants Among Adolescent Tobacco Users Residing in Slum Areas of Bhubaneswar, India: A Cross-Sectional Study
}

\author{
Ansuman Panigrahi ${ }^{1}$ Dheeraj Sharma ${ }^{20}$ Sabita Maharana ${ }^{3}$ \\ ${ }^{1}$ Epidemiology Division, ICMR-NIIRNCD, Jodhpur, Rajasthan, India \\ ${ }^{2}$ Department of Community Medicine, Muzaffarnagar Medical \\ College, Muzaffarnagar, Uttar Pradesh, India \\ ${ }^{3}$ Department of Community Medicine, Shri Jagannath Medical \\ College \& Hospital, Puri, Odisha, India \\ Ind J Med Paediatr Oncol 2021;42:444-450. \\ Address for correspondence Ansuman Panigrahi, MD, Epidemiology \\ Division, ICMR-NIIRNCD, Jodhpur, Rajasthan, 342005, India \\ (e-mail: dr.ansuman3@gmail.com).
}

\begin{abstract}
Introduction Intention to quit is the initial step and a strong predictor of quitting tobacco use.

Objective The aim of this study was to estimate the prevalence and determinants of intention to quit tobacco use among adolescent tobacco users residing in the slum areas of Bhubaneswar, India.

Materials and Methods A community-based cross-sectional study was performed during the year 2017-2018 involving 152 adolescent tobacco users residing in the slums of Bhubaneswar. Multistage cluster random sampling was used to select the study areas.

Results Ninety-three (61.2\%) adolescents had the intention to quit tobacco use. Multivariate logistic regression analysis revealed that the odds of intention to quit tobacco use was significantly higher in adolescents who used it for less than 5 years' duration (adjusted odds ratio (aOR): 2.59; 95\% confidence interval [Cl]: 1.14-5.87),

\section{Keywords}

- intention to quit

- adolescent

- tobacco use

- anti-tobacco messages

- slum those used first tobacco of the day between 31 and 60 minutes after waking up in the morning (aOR: 2.60; 95\% Cl: 1.17-5.79) or more than 60 minutes after waking up (aOR: $6.69 ; 95 \% \mathrm{Cl}: 2.28-19.61$ ), and those who noticed anti-tobacco messages in any media in the past 30 days (aOR: $2.70 ; 95 \% \mathrm{Cl}: 1.02-7.14$ ).

Conclusion The prevalence of intention to quit tobacco use among slum adolescents of Bhubaneswar is $61.2 \%$, which can be enhanced by incorporating the determinants of the intention to quit tobacco use in the existing anti-tobacco schemes.
\end{abstract}

\section{Introduction}

The tobacco epidemic is one of the important public health problems in the world, killing more than 8 million people annually worldwide. ${ }^{1}$ Therefore, tobacco cessation needs special attention, and intention to quit tobacco use is an important predictor of tobacco cessation. ${ }^{2}$ It is difficult to achieve the global targets for reducing tobacco use if current
DOI https://doi.org/ 10.1055/s-0041-1740602. ISSN 0971-5851.

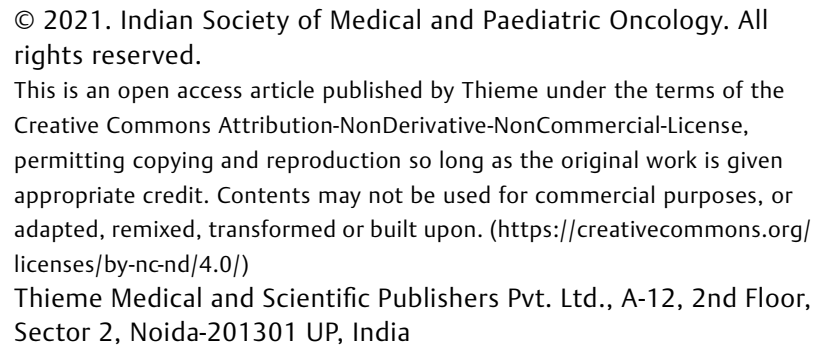

(c) 2021. Indian Society of Medical and Paediatric Oncology. All rights reserved.

This is an open access article published by Thieme under the terms of the Creative Commons Attribution-NonDerivative-NonCommercial-License, permitting copying and reproduction so long as the original work is given appropriate credit. Contents may not be used for commercial purposes, or adapted, remixed, transformed or built upon. (https://creativecommons.org/ licenses/by-nc-nd/4.0/)

Thieme Medical and Scientific Publishers Pvt. Ltd., A-12, 2nd Floor, Sector 2, Noida-201301 UP, India 
tobacco users do not quit although many of them have the intention to quit. In response, the World Health Organization (WHO) has included "offering help to quit" as a vital component in its tobacco control strategy, which focuses on various cost-effective interventions that significantly increase the chances of successfully quitting tobacco among the users. ${ }^{1}$

Globally, there are 1.1 billion adult smokers and at least 367 million smokeless tobacco users, many of whom say that they want or intend to quit. ${ }^{3-5}$ There is a large variation in the prevalence of intention to quit tobacco use in India (12\%$63.3 \%)^{6-9}$ and outside India (54.9\%-82.8\%). ${ }^{10-12}$ Adolescents have exhibited more intention to quit as compared with elders ${ }^{7}$ and various sociodemographic and tobacco userelated factors, such as literacy, health concerns, awareness of tobacco-related damage, having received medical advice to quit tobacco, past quit attempts, and the timing of first tobacco use of the day, have been found to be associated with intention to quit tobacco use. ${ }^{6-8,13}$

Adolescents living in slum areas are a vulnerable population as tobacco use during adolescence increases the risk of persistent nicotine addiction, leading to regular and sustained tobacco use in adulthood. ${ }^{14}$ This vulnerability is further aggravated by undesirable living conditions in slums such as poor housing, overcrowding, and inadequate sanitary and drinking water facilities. Data regarding the intention to quit tobacco use among adolescents living in slums is scarce in India. ${ }^{13,15}$ Hence, this study intends to estimate the prevalence of intention to quit tobacco use among adolescent tobacco users residing in slum areas of Bhubaneswar (primary outcome measure) and determine the factors associated with intention to quit tobacco use among adolescents (secondary outcome measure).

\section{Materials and Methods}

\section{Study Design and Sample Size Determination}

A cross-sectional community-based study was conducted from November 2017 to April 2018 among the adolescents residing in selected slum areas of Bhubaneswar city, the capital city of Odisha situated in the eastern region of India. A sample size of 144 was estimated assuming a prevalence of intention to quit tobacco consumption among adolescent tobacco users as $50 \%$, with an absolute precision of $10 \%$ at a 95\% confidence interval and a design effect of 1.5 .

\section{Sampling Method}

A multistage cluster random sampling technique was used to select the study areas (- Fig. 1). Bhubaneswar city is divided into three geographical zones: North, South-East, and SouthWest comprising 67 wards and 436 slums. Out of the three zones, the North zone was randomly selected; $50 \%$ of the wards having slum areas (11 wards) in this zone were randomly chosen and then from each selected ward, one slum was randomly selected. The sample size was equally distributed among the selected slums. Overall, 478 adolescents aged 10 to 19 years living at least for 2 years in the selected slums were approached for the study. Among them, 165 adolescents who were currently consuming tobacco

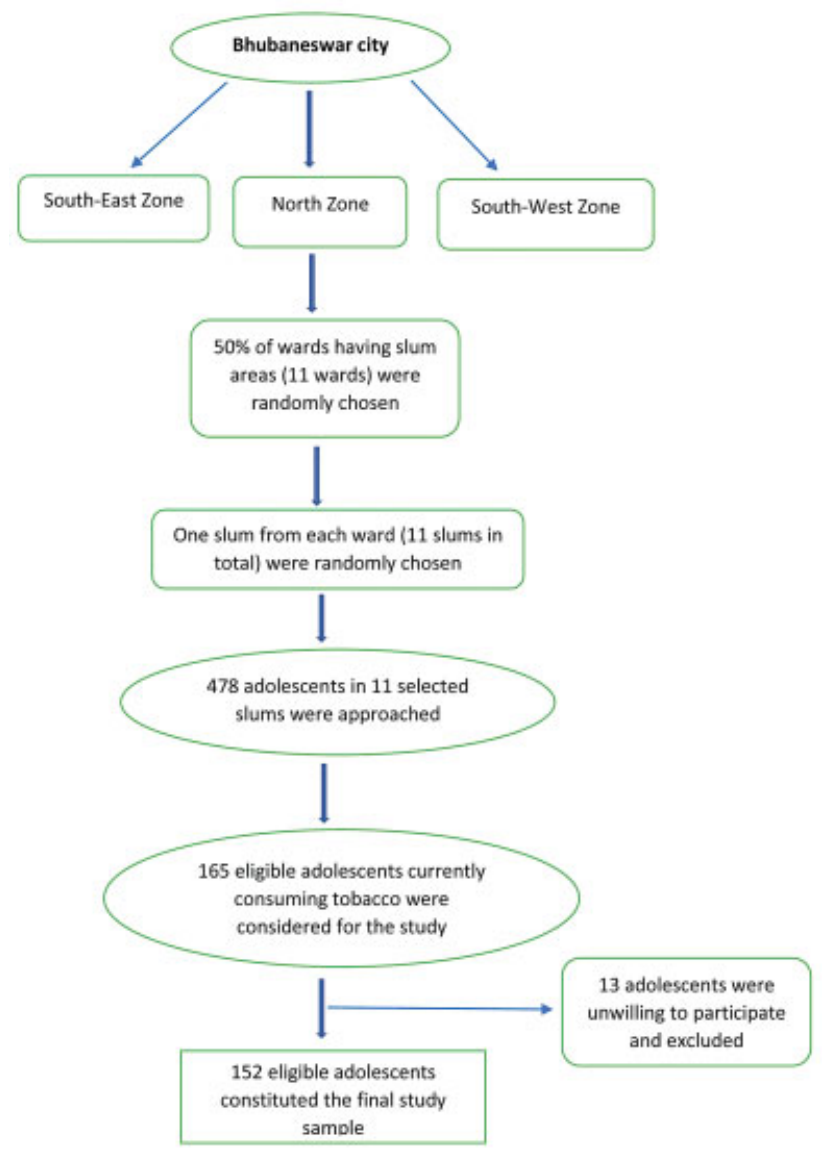

Fig. 1 Flow diagram showing the study selection process.

were considered for the study. In each household, one adolescent was considered for the study purpose and if more than one study subject was found in a household, only one was selected by a simple random sampling technique. Adolescents not consuming any form of tobacco and those unwilling to participate in the study were excluded from the study. Thirteen adolescents did not participate in the study and thus finally 152 eligible adolescents constituted the study sample.

\section{Data Collection}

Prior to the interview, all the eligible adolescents and their parents were informed about the purpose of the study. They were assured that anonymity and confidentiality of their data would be maintained throughout and they could withdraw from the study at any time without giving any reason. The adolescent participants gave assent and their parents provided consent before initiation of the study. A pretested semi-structured schedule was used to collect information regarding sociodemographic characteristics such as age, gender, schooling, type of family, tobacco use by a family member, tobacco use by peers, and parents' advice against tobacco. Also, data on tobacco consumption, type of tobacco, duration of use, frequency of use, time of first tobacco use of the day, quitting attempt in the past 1 year, awareness regarding harmful effects of tobacco, exposure to anti-tobacco media messages in the past 30 days, etc. were collected. 
For data collection about the intention to quit tobacco use, the question "Do you want to quit tobacco use" was asked. Intention to quit was defined as whether the tobacco user was willing to quit within the next month or not. ${ }^{16}$ Response from participants was noted as "Yes/No/Do not Know." The response "No" was considered as no intention to quit tobacco use, while the response "Yes/Do not Know" was taken as an intention to quit tobacco use. ${ }^{17}$ All the adolescent tobacco users were counseled and referred to tobacco cessation centers in Bhubaneswar.

\section{Statistical Analysis}

All data were analyzed using IBM SPSS Statistics for Windows, version 21.0 (Armonk, NY: IBM Corp, 2012) software and expressed as percentages, odds ratio (ORs), and 95\% confidence interval $(\mathrm{CI})$. The outcome measure was the "intention to quit tobacco use" and its relationship with independent variables was first assessed using univariate logistic regression analyses. The variables which had $p<0.1$ in univariate analyses were included in the multivariate logistic regression model. Due to the complex sampling design of the study, sample weights were calculated and considered during the data analysis to obtain more valid results. Collinearity between the variables was not a problem in our study. All $p$-values were two-tailed, and $p<0.05$ was considered statistically significant.

\section{Ethics}

The study was approved by the Institute Ethics Committee of Kalinga Institute of Medical Sciences (Reference number: KIMS/KIIT/IEC/115/2015) dated 29.09.2015 and all the procedures followed were in accordance with the ethical standards and with the Helsinki Declaration of 1964, its later amendments or comparable ethical standards. Appropriate written informed assent and consent were obtained from the adolescent participants and their parents, respectively, before the initiation of the study.

\section{Results}

- Table 1 presents the sociodemographic characteristics and their association with the intention to quit tobacco use among adolescent tobacco users. The mean (SD) age of the study participants was 16.2 (2.7) years. Nearly three-fourth $(n=110,72.4 \%)$ of the study participants were aged $>15$ years, four-fifth ( $n=123,80.9 \%$ ) were males, and more than three-fourth ( $n=118,77.6 \%$ ) were currently not attending school. Univariate analyses revealed that adolescent tobacco

Table 1 Sociodemographic factors associated with intention to quit tobacco among tobacco users staying in the slums of Bhubaneswar, India $(N=152)$

\begin{tabular}{|l|l|l|l|l|}
\hline Sociodemographic Characteristics & Intention to quit $\boldsymbol{n}$ (\%) & Total $\boldsymbol{n}$ & Odds Ratio (95\% Cl) & $p$-Value \\
\hline Age (y) & & & & \\
\hline$\leq 15$ & $29(69.0)$ & 42 & $1.60(0.79-3.22)$ & 0.183 \\
\hline$>15$ & $64(58.2)$ & 110 & 1 & \\
\hline Gender & & & & \\
\hline Male & $76(61.8)$ & 123 & $1.14(0.53-2.44)$ & 0.732 \\
\hline Female & $17(58.6)$ & 29 & 1 & \\
\hline Currently attending school & & & & \\
\hline Yes & $29(85.3)$ & 34 & $4.89(1.92-12.50)$ & 0.001 \\
\hline No & $64(54.2)$ & 118 & 1 & \\
\hline Type of family & & & & \\
\hline Nuclear & $59(70.2)$ & 84 & $2.36(1.27-4.37)$ & 0.007 \\
\hline Joint/Extended & $34(50.0)$ & 68 & 1 & \\
\hline Tobacco use by family members & & & & 0.435 \\
\hline Yes & $66(59.5)$ & 111 & $1.31(0.66-2.62)$ & \\
\hline No & $27(65.9)$ & 41 & 1 & \\
\hline Tobacco use by peers & & & & \\
\hline Yes & $48(60.0)$ & 80 & 1 & 0.731 \\
\hline No & $45(62.5)$ & 72 & $1.11(0.61-2.03)$ & \\
\hline $\begin{array}{l}\text { Youth reported parents advise } \\
\text { against tobacco use }\end{array}$ & & & & \\
\hline Yes & $49(71.0)$ & 69 & $2.17(1.16-4.05)$ & 0.015 \\
\hline No & $44(53.0)$ & 83 & 1 & \\
\hline
\end{tabular}

Abbreviation: $\mathrm{Cl}$ : confidence interval. 
users who were currently attending school (cOR: 4.89; 95\% CI: 1.92-12.50), those belonging to the nuclear family (cOR: 2.36; 95\% CI: 1.27-4.37), and those receiving parents' advice against tobacco use (cOR: $2.17 ; 95 \% \mathrm{CI}$ : $1.16-4.05$ ) had higher odds of intention to quit tobacco use.

- Table 2 reveals the tobacco use-related characteristics and their association with the intention to quit tobacco among adolescent tobacco users. More than half $(n=81$, $53.3 \%$ ) of the adolescents were using smokeless tobacco products, while $30.3 \%$ ( $n=46$ ) were using smoked tobacco and $16.4 \%(n=25)$ were consuming both forms of tobacco. Nearly one-third $(n=48,31.6 \%)$ of study participants were using tobacco for more than 5 years, $84.2 \%$ ( $n=128)$ were using it on daily basis and almost fourfifth $(n=121,79.6 \%)$ did not make any attempt to quit tobacco use in the past 1 year. Univariate analyses showed that the intention to quit tobacco use was significantly higher among those who were using tobacco for less than 5 years' duration (cOR: $3.29 ; 95 \% \mathrm{CI}$ : 1.71-6.36), using tobacco with a frequency less than daily (cOR: $3.77 ; 95 \%$
CI: 1.33-10.68), using first tobacco of the day between 31 and 60 minutes after waking up (cOR: 3.33; 95\% CI: $1.61-$ 6.86 ) or more than 60 minutes after waking up (cOR: 8.09; 95\% CI: 3.28-19.95), who attempted to quit tobacco use in the past 1 year (cOR: 2.58 ; 95\% CI: 1.11-6.02), who had awareness about the harmful effects of tobacco (cOR: 2.10; 95\% CI: 0.99-4.43), and who noticed anti-tobacco messages in any media in the past 30 days (cOR: 4.25; 95\% CI: 2.19-8.23).

- Table 3 shows the multivariate logistic regression model showing the associated factors of intention to quit tobacco use. After adjusting for other variables, adolescents using tobacco for less than 5 years' duration (aOR: 2.59; 95\% CI: 1.14-5.87), those using first tobacco of the day between 31 and 60 minutes after waking up (aOR: 2.60; 95\% CI: 1.17-5.79) or more than 60 minutes after waking up (aOR: 6.69; 95\% CI: 2.28-19.61), and those who noticed antitobacco messages in any media in the past 30 days (aOR: 2.70; 95\% CI: 1.02-7.14) had higher odds of intention to quit tobacco use.

Table 2 Tobacco use-related factors associated with intention to quit among tobacco users staying in the slums of Bhubaneswar, India $(N=152)$

\begin{tabular}{|l|l|l|l|l|}
\hline Tobacco use-related factors & Intention to quit $\boldsymbol{n}$ (\%) & Total $\boldsymbol{n}$ & Odds Ratio $(95 \% \mathrm{CI})$ & $p$-Value \\
\hline Type of tobacco product & & & & \\
\hline Smoked & $27(58.7)$ & 46 & 1 & \\
\hline Smokeless & $51(63.0)$ & 81 & $1.19(0.60-2.37)$ & 0.605 \\
\hline Both & $15(60.0)$ & 25 & $1.06(0.42-2.64)$ & 0.907 \\
\hline Duration of tobacco use & & & & \\
\hline$<5$ y & $73(70.2)$ & 104 & $3.29(1.71-6.36)$ & 0.000 \\
\hline$\geq 5$ y & $20(41.7)$ & 48 & 1 & \\
\hline Frequency of tobacco use & & & & \\
\hline Daily & $73(57.0)$ & 128 & 1 & \\
\hline Less than daily & $20(83.3)$ & 24 & $3.77(1.33-10.68)$ & 0.013 \\
\hline Time of first tobacco use after wakeup & & & & \\
\hline$\leq 30$ min & $21(38.2)$ & 55 & 1 & 0.001 \\
\hline $31-60$ min & $37(67.3)$ & 55 & $3.33(1.61-6.86)$ & 0.000 \\
\hline$>60$ min & $35(83.3)$ & 42 & $8.09(3.28-19.95)$ & \\
\hline $\begin{array}{l}\text { Attempt to quit tobacco } \\
\text { use in the past 1 year }\end{array}$ & & & & \\
\hline Yes & $24(77.4)$ & 31 & $2.58(1.11-6.02)$ & 0.028 \\
\hline No & $69(57.0)$ & 121 & 1 & \\
\hline III-effect awareness & & 122 & $2.10(0.99-4.43)$ & 0.051 \\
\hline Present & $79(64.8)$ & 30 & 1 & \\
\hline Absent & $14(46.7)$ & & & \\
\hline $\begin{array}{l}\text { Noticed anti-tobacco messages } \\
\text { in any media in the past 30 days }\end{array}$ & $55(78.6)$ & 82 & 1 & \\
\hline Yes & $38(46.3)$ & $4.25(2.19-8.23)$ & 0.000 \\
\hline No & & & \\
\hline
\end{tabular}

Abbreviation: Cl: confidence interval. 
Table 3 Multivariate logistic regression analysis showing factors associated with intention to quit among tobacco users staying in the slums of Bhubaneswar, India $(N=152)$

\begin{tabular}{|c|c|c|}
\hline Characteristics & $\begin{array}{l}\text { AOR } \\
(95 \% \mathrm{Cl})\end{array}$ & $p$-Value \\
\hline \multicolumn{3}{|c|}{ Currently attending school } \\
\hline Yes & $0.98(0.25-3.94)$ & 0.983 \\
\hline No & 1 & \\
\hline \multicolumn{3}{|l|}{ Type of family } \\
\hline Nuclear & $1.63(0.76-3.50)$ & 0.207 \\
\hline Joint/Extended & 1 & \\
\hline \multicolumn{3}{|c|}{ Youth reported parents advise against tobacco use } \\
\hline Yes & $1.24(0.56-2.72)$ & 0.596 \\
\hline No & 1 & \\
\hline \multicolumn{3}{|c|}{ Duration of tobacco use } \\
\hline$<5 y$ & $2.59(1.14-5.87)$ & 0.023 \\
\hline$\geq 5 y$ & 1 & \\
\hline \multicolumn{3}{|c|}{ Frequency of tobacco use } \\
\hline Daily & 1 & \\
\hline Less than daily & $1.58(0.43-5.78)$ & 0.489 \\
\hline \multicolumn{3}{|c|}{ Time of first tobacco use after wakeup } \\
\hline$\leq 30 \min$ & 1 & \\
\hline $31-60 \mathrm{~min}$ & $2.60(1.17-5.79)$ & 0.019 \\
\hline$>60 \mathrm{~min}$ & $6.69(2.28-19.61)$ & 0.001 \\
\hline \multicolumn{3}{|c|}{ Attempt to quit tobacco use in the past 1 year } \\
\hline Yes & $0.65(0.23-1.87)$ & 0.425 \\
\hline No & 1 & \\
\hline \multicolumn{3}{|c|}{ III-effect awareness } \\
\hline Present & $0.92(0.34-2.49)$ & 0.863 \\
\hline Absent & 1 & \\
\hline \multicolumn{3}{|c|}{$\begin{array}{l}\text { Noticed anti-tobacco messages in } \\
\text { any media in the past } 30 \text { days }\end{array}$} \\
\hline Yes & $2.70(1.02-7.14)$ & 0.045 \\
\hline No & 1 & \\
\hline
\end{tabular}

Abbreviations: AOR: adjusted odds ratio; $\mathrm{Cl}$ : confidence interval.

Note: Model fit statistics: Nagelkerke's pseudo- $R^{2}=0.322$, Model Wald $\mathrm{F}=4.167, p=0.000$. Classification table reports that the overall expected model performance is $72.4 \%$; that is, $72.4 \%$ of the cases can be expected to be classified correctly by the model.

\section{Discussion}

Various epidemiological studies have shown that there are higher rates of tobacco usage among the slum population $^{18-20}$, and tobacco use during adolescence increases the risk of regular tobacco use in adulthood. ${ }^{14}$ The present study assessed the prevalence of intention to quit tobacco use and its determinants among slum adolescents which would help in designing strategies to check the tobacco menace in slum areas, thereby contributing to the antitobacco campaign in the country. In the present study, $61.2 \%$ (58.7\% smokers, 63\% smokeless tobacco users) of adolescent tobacco users residing in the slum areas of
Bhubaneswar had the intention to quit tobacco use. Tobacco cessation treatment navigators can be deployed in slum areas to help these tobacco users choose and adhere to cessation treatment. It was reported by Agaku et al in a Nigerian study that approximately $82.8 \%$ of adolescent cigarette smokers and $80.5 \%$ of adolescent smokeless tobacco users intended to quit tobacco use within 12 months. ${ }^{11}$ Tworek et al observed in their study in the United States that the prevalence of intention to quit all tobacco use was $52.8 \%$ among current youth tobacco users. ${ }^{10}$ In another study conducted in Malaysia, Fathelrahman et al showed that approximately $55.5 \%$ of smokers had the intention to quit tobacco use. ${ }^{17}$ The differences in the prevalence of intention 
to quit tobacco use could be attributed to the variation in the methodologies adopted in the studies, study setting, and sociocultural factors.

The present study revealed that adolescent tobacco users who were using tobacco for less than 5 years' duration had increased intention to quit tobacco use as compared with those who were using it for $\geq 5$ years. This finding is supported by the results reported in earlier studies as the chance of intention to quit tobacco use diminishes when tobacco is used for a prolonged period. ${ }^{6,21}$ This might be explained by the fact that those who used tobacco for less number of years did not develop nicotine dependence to the extent as found in those using tobacco for more number of years.

It was observed in our study that the adolescents who consumed the first tobacco of the day 30 minutes after waking up had higher odds of intention to quit tobacco use as compared with those who used tobacco within 30 minutes after waking up. Yang et al also reported in their study that those with first tobacco use more than 30 minutes after waking up had approximately 2.69 times increased odds of intention to quit tobacco use as compared with those who used tobacco within 30 minutes after waking up. ${ }^{22}$ Similarly, in another study, the odds of intention to quit smoking increased approximately 1.4 times in those using the first smoke of the day after 30 minutes of waking up as compared with those using the first smoke of the day within 30 minutes of waking up. ${ }^{21}$ This result has also been supported by other studies. ${ }^{7,23,24}$ It indicates that those who experienced less craving for tobacco after waking up had a higher intention to quit tobacco use as compared with those who experienced more urge for tobacco after waking up.

In this study, adolescent tobacco users who noticed antitobacco messages in any media in the past 30 days had approximately 2.7 times higher odds of intention to quit tobacco use as compared with those who did not notice any such message. In a survey conducted in 17 countries during 2008-2011, the association between the intention to quit tobacco use and exposure to anti-tobacco messages through single/multiple media channels was statistically significant, with adjusted ORs ranging from 1.3 to $3.2 .^{25}$ The result of our study is concurrent with the findings of earlier studies: tobacco users who had seen or heard anti-tobacco messages through television/radio/newspaper/magazine/billboards/ hoardings had significantly more intention to quit tobacco use than their counterparts. ${ }^{7,9,23}$ This might be due to the reason that anti-tobacco information through mass media channels might be effectively helping tobacco users understand the harmful impacts of tobacco consumption and thereby prompting them to consider quitting tobacco use.

The study has a few limitations. First, because of the crosssectional nature of the study causal inferences cannot be established. Second, as the information is based on selfreporting, there might be an introduction of social desirability response bias. Third, we did not use the question "when are you planning to quit tobacco (1) within the next month (preparation), (2) within the next 6 months (contemplation), (3) sometime in the future beyond 6 months (some interest), and (4) not planning to quit (no interest)?" and thus it is difficult to comment on different stages of change before quitting tobacco. Future research including longitudinal studies is needed to clearly understand different stages before quitting tobacco and identify its determinants.

\section{Conclusion}

The majority of adolescent tobacco users (61.2\%) residing in the slums of Bhubaneswar had an intention to quit tobacco use. Our findings suggest that emphasizing the factors such as duration of tobacco use, the timing of first tobacco use of the day after waking up, and exposure to anti-tobacco messages in the existing tobacco control strategies could be useful in positively impacting the intention to quit and thereby checking the tobacco epidemic.

\section{Authors' Contributions}

The manuscript has been read and approved by all authors, and that the requirements for authorship have been met, and that each author believes that the manuscript represents honest work.

Funding
None.

Conflicts of Interest

The authors declare that there is no conflict of interest.

\section{References}

1 World Health Organization. WHO report on the global tobacco epidemic 2019: offer help to quit tobacco use; 2019. Accessed August 18, 2021 at: https://www.who.int/publications/i/item/ 9789241516204

2 Balmford J, Borland R, Burney S. The influence of having a quit date on prediction of smoking cessation outcome. Health Educ Res 2010;25(04):698-706

3 World Health Organization. Who global report on trends in prevalence of tobacco smoking 2000-2025. 2nd ed. Geneva2018

4 Asma S, Mackay J, Yang Song S, et al. The GATS Atlas: Global Adult Tobacco Survey. Atlanta, GA2015

5 Gakidou E, Afshin A, Abajobir AA, et al; GBD 2016 Risk Factors Collaborators. Global, regional, and national comparative risk assessment of 84 behavioural, environmental and occupational, and metabolic risks or clusters of risks, 1990-2016: a systematic analysis for the Global Burden of Disease Study 2016. Lancet 2017;390(10100):1345-1422

6 Islam K, Saha I, Saha R, Samim Khan SA, Thakur R, Shivam S. Predictors of quitting behaviour with special reference to nicotine dependence among adult tobacco-users in a slum of Burdwan district, West Bengal, India. Indian J Med Res 2014;139(04): 638-642

7 Kar SS, Sivanantham P, Rehman T, Chinnakali P, Thiagarajan S. Willingness to quit tobacco and its correlates among Indian tobacco users-Findings from the Global Adult Tobacco Survey India, 2016-17. J Postgrad Med 2020;66(03):141-148

8 Panda R, Venkatesan S, Persai D, Trivedi M, Mathur MR. Factors determining intention to quit tobacco: exploring patient responses visiting public health facilities in India. Tob Induc Dis 2014;12(01):1. Doi: 10.1186/1617-9625-12-1

9 Surani NS, Gupta PC, Fong TG, Pednekar MS, Quah AC, BansalTravers M. Intention to quit among Indian tobacco users: findings 
from International Tobacco Control Policy evaluation India pilot survey. Indian J Cancer 2012;49(04):431-437

10 Tworek C, Schauer GL, Wu CC, Malarcher AM, Jackson KJ, Hoffman AC. Youth tobacco cessation: quitting intentions and past-year quit attempts. Am J Prev Med 2014;47(02, Suppl 1):S15-S27

11 Agaku I, Akinyele AO, Omaduvie UT. Evaluation of factors influencing intention to quit smokeless and cigarette tobacco use among Nigerian adolescents. Niger Med J 2012;53(01):31-36

12 Butler KM, Ickes MJ, Rayens MK, Wiggins AT, Ashford K, Hahn EJ. Intention to quit smoking and polytobacco use among college student smokers. Prev Med Rep 2018;10:72-75

13 Dhumal GG, Pednekar MS, Gupta PC, et al. Quit history, intentions to quit, and reasons for considering quitting among tobacco users in India: findings from the Tobacco Control Policy Evaluation India Wave 1 Survey. Indian J Cancer 2014;51(Suppl 1):S39-S45

14 Chadda R, Sengupta S. Tobacco use by Indian adolescents. Tob Induc Dis 2002;1(02):111-119

15 Arora M, Tewari A, Tripathy V, et al. Community-based model for preventing tobacco use among disadvantaged adolescents in urban slums of India. Health Promot Int 2010;25(02):143-152

16 Aryanpur M, Masjedi MR, Mortaz E, et al. Intention to quit smoking and associated factors in smokers newly diagnosed with pulmonary tuberculosis. Tanaffos 2016;15(01):17-24

17 Fathelrahman AI, Omar M, Awang R, et al. Smokers' responses toward cigarette pack warning labels in predicting quit intention, stage of change, and self-efficacy. Nicotine Tob Res 2009;11(03): 248-253
18 Acharyya T, Kaur P, Murhekar MV. Prevalence of behavioral risk factors, overweight and hypertension in the urban slums of North 24 Parganas District, West Bengal, India, 2010. Indian J Public Health 2014;58(03):195-198

19 Chockalingam K, Vedhachalam C, Rangasamy S, et al. Prevalence of tobacco use in urban, semi urban and rural areas in and around Chennai City, India. PLoS One 2013;8(10):e76005

20 Mukherjee K. Study on tobacco consumption patterns and its determinants in an urban slum in New Mumbai. Int J Epidemiol Res 2015;2:164-171

21 Khan ZA, Goel R, Mukherjee AK, Khan T. Prevalence and predictors of intention to quit tobacco smoking in smokers of rural area of North India (Haryana). Int J Community Med Public Health 2018; 5:1617-1622

22 Yang M, Essien E, Sansgiry S, Wu Ih, Peters R, Abughosh S. Predictors of intention to quit cigarette smoking among Chinese adults. J Behav Health 2012;1:93-101

23 Reddy MM, Kanungo S, Naik BN, Kar SS. Willingness to quit tobacco smoking and its correlates among Indian smokers Findings from Global Adult Tobacco Survey India, 2009-2010. J Family Med Prim Care 2018;7(06):1353-1360

24 Fagan P, Augustson E, Backinger CL, et al. Quit attempts and intention to quit cigarette smoking among young adults in the United States. Am J Public Health 2007;97(08):1412-1420

25 Centers for Disease Control and Prevention (CDC) Antismoking messages and intention to quit - 17 countries, 2008-2011. MMWR Morb Mortal Wkly Rep 2013;62(21):417-422 